rushes for ward through the auricle into the ventricle, throwing aside by its own weight or force the now relaxed valves. On it flows, yet passively as regards the auricle itself, and quite independently of any action it may or can then exert. Full, even to a slight degree of distension, when the diastole of the ventricle begins, it continues full all the time the diastole is in progress.

6. Does the auricle, then, when it does act, not send any blood into the ventricle? Does it not at this stage "empty" itself into the ventricle? For just prior to the ventricular contraction it is itself truly in action; its muscular appendages may be seen in action, whether "forcibly" or not. Does the auricle not, then, propel some blood into the ventricle? No, or nothing save a drop or two, or a very few drops. For, Q E.D., the ventricle is already full.

7. What, then, does Dr. Gairdner precisely mean by the word "emptying" in respect of the auricle? It is intelligible as regards the ventricle. As regards the auricle it is to me unintelligible. Moreover, what does he precisely mean by the word "forcible" in respect of the action of the auricle? I learn from a dictionary at my elbow that "forcible" means "impetuous-powerful-done by force or violence." I also learn that to "empty" is "to deprive of contents - to exhaust-to evacuate- to become empty"; and, further, that to be or become "empty" is to be "void, having nothing in it." Has the auricle, then, nothing in it when it evacuates its contents in to the ventricle? How often do words cheat us! "Credunt homines rationem suam verbis imperare; sed fit etiam ut verba vim suam super intellectum retorqueant."

(To be concluded.)

\section{VARICOCELE, AND ITS CURATIVE OPE- RATION BY SUBCUTANEOUS WIRE LOOP.}

\section{Bx RICHARD BARWELL, F.R.C.S.,} SURGEON TO CHARING-CROSS HOSPITAL.

THE mode of operating on nævus by subcutaneous wire loop, which $I$ advocated in a former paper (THE LANCET, May 8th), is, with certain modifications, also applicable to the curative operation for varicocele, and is, $I$ believe, the safest means of destroying the varicose veins at this part. Before, however, describing this method, it would be well to say a few words concerning the malady, and the motives which should cause us to operate or to abstain.

The veins of the lower part of the cord may become varicose from a number of causes, and yet the disease is rarely seen on the right side. When we consider that the malady may follow a blow, of which causation I have seen two examples, and that it may very commonly be traced to evil habits in youth, it would seem strange that such occurrences, which certainly ought to affect both sides, only produce varicocele on the left, rarely on both, hardly ever on the right alone; I say this would seem strange did we not take into account the predisposing causes, of which there are two: one, the termination of the spermatic vein, usually held to be all-sufficient; the other, and in my belief the more important, being the position of the lower part of the colon across the vein, which intestine, being in careless youth often overloaded, affords a marked obstacle to the return of venous blood.

Whatever the immediate cause may be, we find within the scrotum of a person thus affected the enlarged veins, aptly compared to a bunch of earth-worms, extending from the testicle upwards, the scrotum on that side lax and long, the testicle smaller and softer than the other, and often the seat of sharp, lancinating, more or less frequently recurrent pains, as well as of continuous aching, sometimes dull, sometimes severe.

Now, these two points-the flabbiness and smallness of the testicle, and the frequency or severity of the painshould cause us to recommend or withbold operation. There is no doubt that a elight or moderate degree of varicocele may be kept in abejance, may even be improved, by the use of a suspensory bandage or of a truss, and under such circumstances the malady will be painless. The testicle will hardly diminish in size. Nevertheless I believe that cure of this complaint by such means is excessively rare, nor do I think that the testicle from which the varicocele springs is of much use. But, as long as the organ retains a certain amount of harduess and of size, I do not feel justified in recommending an operation, and if no very palpable difference in the two organs be present, I should even strongly dissuade a patient from such procedure, unless he were suffering much pain. On the other hand, is the testicle of the affected side be markedly small and soft, particularly if the diminution have been rapid and be still going on, I should recommend obliteration of the veins, even though the accompanying pain were trivial; a fortiori, I would strongly recommend it if the pain be pretty severe. Even considerable pain alone (neuralgia being eliminated) is sufficient justification for operation by a method which, in my experience, is free from danger.

I cannot say that freedom from danger is the quality of every operation for varicocele. The plan of passing two needles beneath the veins, the one a short distance above the other, casting round each a figure-of-8 ligature, and dividing the vessels between them, has not infrequently been followed by præmia and death. Ricord's subcutaneous ligature is in many ways imperfect; præmia has resulted from it, and return of the disease also occurs. Other methods might also be named, such as Tufnell's substitution of wire for the thread which Ricord uses, and this is doubtless the best that has hitherto been described. Among the okjections to it is complication.

The method which I adopted several years ago, and which I have very frequently used, is as follows:-First, it is most important that the vas deferens and spermatic artery be separated from the veins. This is best done by the surgeon standing on the patient's left (supposing the disease to be on that side), and taking that half of the scrotum, about an inch abnve the testicle, between the left finger and thumb, and feeling for the duct by rubbing the two surfaces of the bag gently together while its walls glide from his grip. When he has thus brought the duct and artery from among the venous plexus and holds them between his thumb and finger-tip, he must let them slip away to the back, so that he will enclose the veins within the circle of his finger and thumb and exclude from it the artery and the vas deferens. The digit tips and slightly compressed scrotum will thus separate the one set of vessels from the other. If, in seeking for the duct, the surgeon have allowed a few veins to slip away with it, he can begin again, with the advantage of having no longer the whole mass, but only a few vessels, to deal with. If he be not sure of having successfully isolated this important part, he must examine the condition of things with his right hand while keeping the left in the same position. Supposing this separation accomplished, the bit of scrotum between the finger tips is to be squeezed rather tight, and a needle, armed with iron or silver wire, not too fine, thrust straight through above them. Now the part may be released from grasp, and the needle passed in again at the puncture of exit, in front of the veins, and out at the first place of entrance. Thus at one opening protrude the two ends of the wire, and at the other a loop; by drawing on the ends the loop is pulled into the scrotal cavity, and closely surrounds the varicocele. Each end is passed through a hole in the little instrument I depicted in my former paper, and drawn tight enough to make the veins below swell, bulge, and partly consolidate. Every other day, or every day if time be an object, the wire may be tightened until it bas cut through all the consolidated veins, and has come away. No suppuration nor apparent inflammation accompanies the process. The patient need not be confined to his bed after the first forty-eight hours.

One caution must be given. In passing the needle the second time-i. e., in front of the veins, -its course must be entirely in the cavity of the scrotum. If, from over-anxiety to include every vein, or from other cause, some of the lining fascia be strangulated in the loop, the case will be considerably retarded, and some amount of suppuration, accompanied by swelling in the walls of the sac, is likely to ensue. The operation, well performed, is very slightly painful. I have several times completed it without an 
anæsthetic. Neitber is it followed by pain; indeed, where aching of the testicle has previously been pretty severe, relief is the immediate result.

Rather than give the details of any one case, I prefer to offer here an analysis of my results. I have operated on thirty-two cases. Not one has been followed by shiverings, erysipelas, or other dangerous symptom. Three had some suppuration : the pus found its way out of the first puncture in two of these; in the third, a small abscess formed in the walls of the scrotum, an opening a third of an inch long emptied it, and it rapidly healed. In every ase the testicle has begun to resume its size and hardness soon after operation. Those that returned to observation after a year or more were found to have quite recovered normal condition, except one. Two cases I saw after five and after seven zears. The former had, through bad habits, a double varicocele; the testicles, previous to operation, were very small and soft; he was pretty nearly emasculate; now the organs are firm, healtby, and very good. The other, seen after seven years, had become the father of two children, stated to be strong and bealthy. The one case referred to above, which after two years had not recovered normal condition, was one of left varicocele; the testicle was at the time of operation quite flabby; it was at the end of two years certainly better, but still very soft, and the patient believed it to have regained function; the man was a very feeble person, of phthisical history. Although I have asked all my patients to call upon me in case there were any return of the disease, I have never seen one of them with such complaint. George-street, Hanover-square.

\section{OBSERVATIONS ON MINERS' NYSTAGMUS. A NEW DISEASE.}

BY CHARLES BELL TAYLOR, M.D., F.R.C.S. E., SURGEON TO THE NOTIINGHAM AND MTDLAND EYE INFIRMARY.

DURINa the past twelve years the neighbouring colliery district has furnished me with several examples of a peculiar malady which I have not found described in any of our text-books, and which I presume to be, therefore, a comparatively new or hitherto unstudied affection. I have called it " miners' nystagmus" from the peculiar oscillating motions of the eyeball which are characteristic of the disease, and from the fact that I have only observed it occurring in adults, and independent of other ocular defects, among the men employed in the coalpits of this and the neighbouring counties.

It was formerly supposed that nystagmus was incurable, always developed itself in infancy (although it might not in slight cases attract attention until the patient began to read), and was caused either by imperfect nervous perception or structural changes in the transparent media of the eyeball. In miners' nystagmus, however, the disease is usually curable, is developed in adults and aged persons previously healthy, is not accompanied by disease of the nerve or structural change of the eyeball, and is, as a rule, only to be noticed when the patient attempts fixation, especially in a stooping position. The oscillating motions are cansed by alternating contractions of the recti or oblique muscles, and, in all the cases I have observed, have been either horizontal or rotatory.

The affection appears to be analogous to writers' cramp, pianists' and telegraphists' cramp, or the similar affection of the gastrocnemii occasionally observed in ballet-dancers. It may be developed in any or all of the muscles supplied by the third nerve, and is clearly caused by the overtaxing of these organs. The patient makes a great and sustained effort to see in an imperfect light; the muscles engaged in the accommodative strain are overburdened, in course of time give way, and at last, whenever called upon, just as in the analogous cases cited above, become, as it were, agitated and fluttered, escape from the control of the will, and perform irregular motions. It is clear from these facts that in all cases in which a considerable degree of exertion of the ocular muscles is required for distinct vision nystagmus may, under certain concomitant favouring circumstances, be developed. Hitherto the cause of nystagmus has been referred to, and might usually be readily detected in, the ejeball itself, but these cases demonstrate that causes external to the organ, and independent of any structural or apparent functional changes, may occasion all the phenomena of that disease, or, more properly speaking, symptom of disease. Nystagmus generally persists so long as its cause remains, and, if developed in childhood, may continue even after its removal; but in 'miners' nystagmus" the aphorism sublata causa tollit effectus applies, and, as a rule, change of occupation and working in a good light are all that is necessary to effect a cure. In my first case, sent by my friend Dr. Forbes, of Eastwood, some years ago, I did not recognise the cause of the affection, and tried various remedies-such as the continuous galvanic current, blue spectacles, atropine, tenotomy of the affected muscles, and tonic and alterative remedies - with but little benefit. Since then similar cases have led me to a perception of the true cause of the disease, and the proper method of cure, which, as I have just remarked, consists essentially in a change of occupation, supplemented by such auxiliary treatment as may, in each case, appear to be specially indicated. It is worthy of note that the men are very apt to attribute their imperfect sight to one or other of the accidents which are so deplorably frequent among workmen underground. This is natural, of course, and acquires importance from a medico-legal point of view; but I have hitherto been unable to satisfy myself that in any case the accident had caused the affection, though readily inclined to grant that the nervous commotion and depressing influence of such injuries may aggravate an already existing disease, specially one so apt to be intensified by any nervous excitement.

In the three cases at present under treatment, and reported below, as samples of nine or ten otbers which I have had under my care, this disposition is evident in two, though there is little doubt that sight had been failing some time before the accidents to which the men ascribed their imperfect vision.

Case 1.-James B-, aged fifty-six, of Staveley, came under my care on Feb. 3rd, 1875, complaining of dimness of vision and consequent inability to work. On examination with the ophthalmoscope, and directing the patient to look "inwards," the eyeballs immediately manifested the peculiar oscillating motions characteristic of " miners" nystagmus." The motions were aggravated by stooping or by an imperfect light. He stated that he had worked in a pit since he was seven years of age, and had not noticed anything wrong with his sight until four months ago, when he was crushed with some falling bind. He admitted, however, on further examination, that vision had been dimmish for some time, probably a year before the accident. He had been blistered by his surgeon, and had a seton in his back, "to elear the sight," without benefit. The optic discs were healthy, and there was no disease of the eyeball to account for the involuntary motions. He was ordered small doses of iodide of potassium as a placebo, and directed to abandon his occupation underground. Under this treatment his sight gradually improved, and on the date of his last visit (May 15th) was nearly normal, although by fixing his attention on any small object, especially while stooping, it was still possible to set the eyeballs oscillating to a slight degree.

CASE 2-Philip A-, of Seamer, near Staveley, aged thirty-seven, came under my care in January, 1875, complaining of dimness of vision, which, he says, was caused by a crush which be received in the pit on Nov. 25 th, 1874 . Has worked in a pit since ten years of age, and sight has always been good until lately. Is positive that the accident has caused his imperfect sight. Nothing peculiar is to be observed on glancing furtively at the patient, awaiting his turn for examination, and his eyeballs are at rest; but on questioning and looking at him, the effort to return your gaze is quite sufficient to set the eyeballs rolling rapidly from side to side. No disease or structural change was manifest on ophthalmoscopic examination; the patient had recovered from his accident, and was otherwise in good health. He was ordered to abandon his occupation, get some work on the pit-bank above-ground, and to take acetate of strychnia thrice daily, in increasing doses. Under this treatment he rapidly improved, and on May 20th, the date of his last visit, it was diffcult, either by stooping, fixation, 